\title{
ANALISIS KELAYAKAN BISNIS PRODUK KARET REMAH MENJADI KARET SIR 20 DI PT. ACEH RUBBER INDUSTRIES KABUPATEN ACEH TAMIANG
}

\author{
Muslimah ${ }^{1}$, Fahmi Ramadana ${ }^{2}$ \\ ${ }^{1}$ Dosen Fakultas Pertanian Universitas Samudra \\ ${ }^{2}$ Mahasiswa Program Studi Agribisnis Fakultas Pertanian Universitas Samudra
}

\begin{abstract}
Abstrak
Penelitian ini bertujuan untuk untuk mengetahui kelayakan finansial bisnis produk karet menjadi karet sir 20 di PT. Aceh Rubber Industries Kabupaten Aceh Tamiang. Penelitian ini menggunakan metode studi kasus. Lokasi Penelitian yaitu di Dusun Damai Paya Ketenggar, Kecamatan Manyak Payed Kabupaten Aceh Tamiang. Objek Penelitian ini hanya dibatasi pada industri pengolahan karet pada PT. Aceh Rubber Industries. Ruang Lingkup penelitian ini meliputi kelayakan finansial pada bisnis produk karet remah menjadi karet SIR 20. Hasil perhitungan penelitian ini diperoleh NPV $=6.871 .582 .204$ (lebih besar dari nol), yang artinya usaha tersebut layak untuk dilanjutkan. Rata-rata $I R R=24,16 \%$ lebih besar dari tingkat bunga yang berlaku 5,25\% sehingga usaha tersebut layak untuk diusahakan dan rata-rata Net B/C Ratio $=1,75$ (lebih besar dari 1) maka usaha tersebut layak untuk dikembangkan bila ditinjau dari aspek segi finansial, dilihat dari kemampuan payback period (PBP) usaha ini relatif cepat dapat mengembalikan modal, tepatnya rata-rata 3,3 tahun (lebih kecil dari umur proyek), maka usaha tersebut layak untuk diusahakan dan dikembangkan.
\end{abstract}

\section{Kata kunci: karet remah,karet SIR 20, kelayakan bisnis}

\section{PENDAHULUAN}

Industri adalah suatu usaha atau kegiatan pengolahan bahan mentah atau barang setengah jadi menjadi barang jadi yang memiliki nilai tambah untuk mendapatkan keuntungan. Kegiatan Industri merupakan salah satu upaya untuk meningkatkan kesejateraan penduduk. Selain itu industrialisasi juga tidak terlepas dari usaha untuk meningkatkan mutu sumberdaya manusia dan kemampuan untuk memanfaatkan sumber daya alam secara optimal.

Pengembangan agroindustri pada hakikatnya merupakan upaya mendayagunakan sumber daya alam dan sumber daya pembangunan lainnya agar lebih produktif, mampu mendatangkan nilai tambah, memperbesar perolehan devisa dan menyerap banyak tenaga kerja dengan memanfaatkan keunggulan koparatif dan kompetitif yang dimilikinya. Pengembangan subsektor ini diarahkan menciptakan keterkaitan yang erat antara sektor pertanian dan sektor industri, sehingga mampu menopang pembangunan ekonomi nasional" (Soekartawi, 2001:5).

Karet alam merupakan salah satu komoditi perkebunan yang sangat penting peranannya dalam perekonomian Indonesia karena karet menjadi urutan ketiga dalam 10 komoditi utama ekspor Indonesia (Kemendag RI, 2015). Pengolahan karet di Indonesia hanya sebatas menjadi produk karet setengah jadi. Itu terbukti bahwa $82 \%$ produksi karet alam Indonesia diekspor dalam bentuk karet mentah sementara konsumsi karet domestik untuk memproduksi barang-barang karet baru baru mencapai $18 \%$. Hal ini karena penyerap karet nasional dan proses hilirisasi di Indonesia yang kurang maksimal (Kementerian Perindustrian, 2012).

Tabel 2. Penyerapan Karet Nasional

\begin{tabular}{|c|r|l|}
\hline Persentase & Produksi & \multicolumn{1}{c|}{ Keterangan } \\
\hline $100 \% 11000$ & 3,1 juta ton & Produksi karet nasional \\
\hline $82 \%$ & 2,542 juta ton & Ekspor \\
\hline $18 \%$ & 558 ribu ton & Diolah \\
\hline
\end{tabular}


Bahan olah karet dan Standard Indonesian Rubber yaitu berasal dari Bokar. Bahan olah karet dan Standard Indonesian Rubber yaitu berasal dari Bokar. Bokar adalah lateks kebun (getah pohon karet) dan gumpalan lateks kebun yang (Hevea brassiliensis Muell Arg) (SNI06-2047 Tentang Bahan Olahan Karet).

Standard Indonesian Rubber adalah karet alam yang diperoleh dengan pengolahan bahan olah karet yang berasal dari getah batang pohon Hevea brasiliensis Muell Arg secara mekanis dengan atau tanpa kimia, serta mutunya ditentukan secara spesifikasi teknis. (SNI-06-1903-2000 Tentang Standard Indonesian Rubber). Menurut SNI 06-19032000, SIR digolongkan dalam 6 jenis mutu yaitu: SIR 3 CV ( Constant Viscosity), SIR 3 L ( Light), SIR 3 WF ( Whole Field), SIR 5, SIR 10 dan SIR 20. SIR 3 CV, SIR 3 L dan SIR 3 WF dari lateks. SIR 5, SIR 10 dan SIR 20 dari koagulum lateks . Untuk memilih jenis bahan olah yang sesuai dengan rencana produksi, produsen SIR dapat berpedoman kepada SNI 06-2047 revisi terakhir (Standar Bahan Olahan Karet).

Analisis keuangan sangat diperlukan dalam menjalankan suatu usaha yaitu untuk mengetahui kelayakan usaha dari sisi keuangan, perencanaan dan pengelolaan usaha dapat dianalisis dengan aspek finansial kelayakan

\section{TINJAUAN PUSTAKA Industri}

Menurut Soekartawi (2005), Industri adalah suatu kegiatan ekonomi yang melakukan kegiatan mengubah barang atas dasar secara mekanik, kimia atau dengan tangan, sehingga menjadi barang jadi, atau mengubah barang dari kurang nilainya menjadi barang yang lebih tinggi nilainya dengan maksud mendekatkan produk tersebut kepada konsumen akhir, termasuk dalam kegiatan jasa industri dan pekerjaan perakitan.

Peranan sektor industri dalam kegiatan pembangunan semakin penting. Pemerintah terus berusaha menyeimbangkan peranan sektor industri terhadap sektor pertanian, untuk menciptakan struktur ekonomi yang seimbang dimana terdapat kemampuan industri maju yang didukung oleh pertanian yang tangguh.
Berdasarkan kenyataan diatas, maka industri yang mengolah hasil-hasil pertanian di Indonesia memegang yang strategis (Soekartawi,2000).

Agroindustri adalah industri yang berbahan baku utama dari produk pertanian. Studi agroindustri pada konteks ini adalah menekankan pada food processing management dalam suatu perusahaan produk olahan yang berbahan baku utamanya adalah produk pertanian. Suatu industri yang menggunakan bahan baku dari pertanian dengan jumlah minimal 20\% dari jumlah bahan baku yang digunakan adalah agroindustri. Arti kedua adalah agroindustri diartikan sebagai suatu tahapan pembangunan sebagai kelanjutan dari pembangunan pertanian, tetapi sebelum tahapan pembangunan tersebut mencapai tahapan pembangunan industri (Soekartawi, 2000).

Pembangunan agroindustri dihadapkan pada berbagai tantangan, baik tantangan atau permasalahan yang ada di dalam negeri atau di luar negeri. Beberapa permasalahan agroindustri khususnya di dalam negeri antara lain :

a) Beragamnya permasalahan berbagai agroindustri menurut macam usahanya, khususnya kurang tersedianya bahan baku yang cukup dan kontinu.

b) Kurangnya peran agroindustri di pedesaan karena masih berkonsentrasi pada agroindustri di perkotaan.

c) Kurangnya konsistennya kebijakan terhadap agroindustri.

d) Kurangnya fasilitas permodalan (perkreditan) dan penggunaan prosedurnya yang ketat (Soekartawi, 2000)

Industri Karet merupakan salah satu industri yang mengelola komoditas karet alam menjadi suatu produk jadi maupun produk setengah jadi yang dapat memberikan nilai tambah. Didalam mengelola pengolahan karet mempunyai standar mutu karet yang telah ditetapkan oleh badan standarisasi nasional Indonesia. Standar Nasional Indonesia (SNI) terkait ekspor karet yaitu SNI 06- 1903- 
2000 Standard Indonesian Rubber (SIR). SNI 06-1903-2000 diberlakukan wajib artinya SIR yang diperdagangkan ke luar negeri wajib memenuhi SNI 06- 1903- 2000 atau revisinya dengan Peraturan Menteri Perdagangan (Permendag) Nomor 10/M-DAG/PER/4/2008 tentang Ketentuan Karet Alam Spesifikasi Teknis Indonesia (Standard Indonesian Rubber (SIR) Yang Diperdagangkan ke Luar Negeri. (SNI 06-1903-2000 Tentang Standard Indonesian Rubber).

\section{Karet SIR-20}

Tabel 3. Persyaratan mutu kadar kandungan yang harus dimiliki oleh masing- masing produk SIR berdasarkan (SNI 06-1903-2000 Tentang Standard Indonesian Rubber).

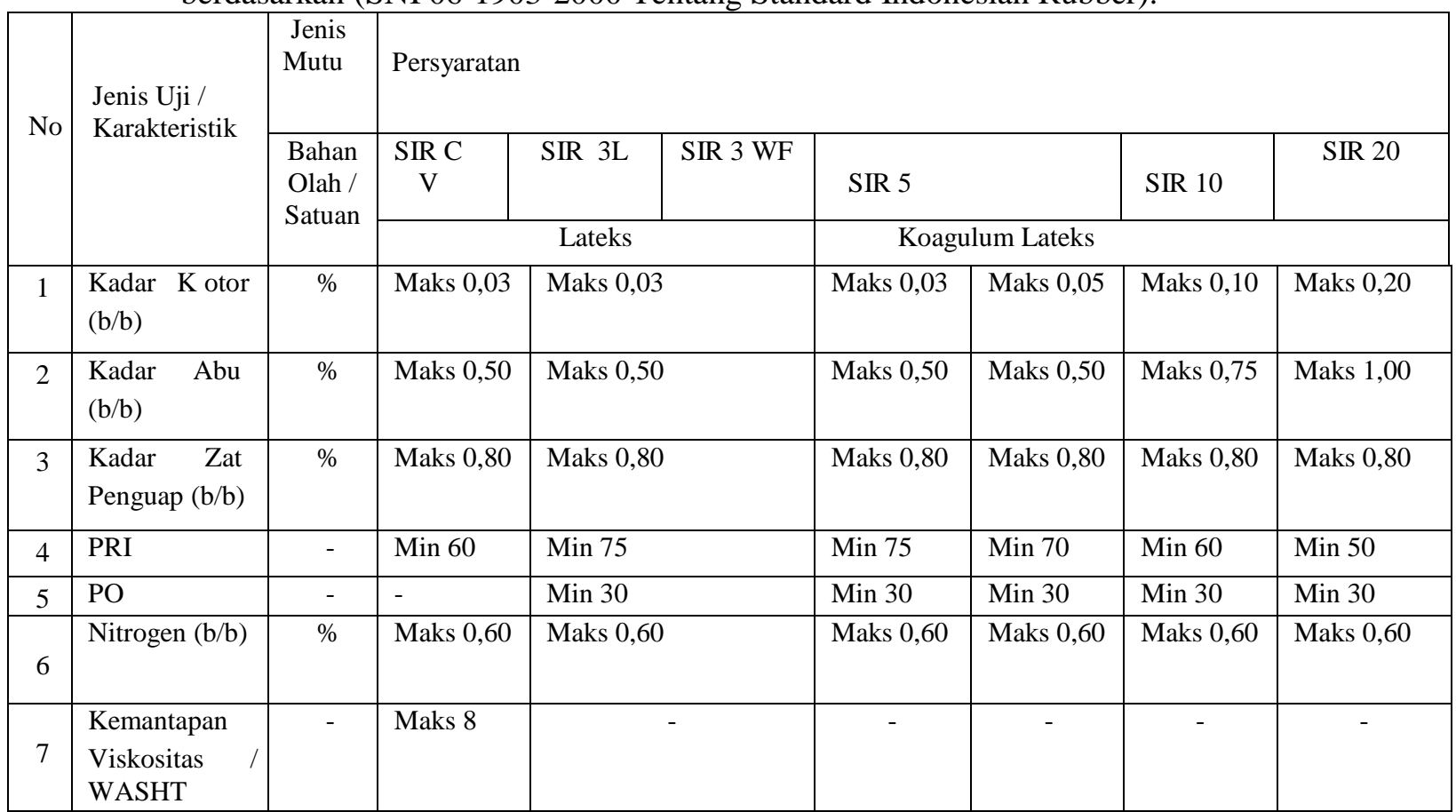

Sumber : SNI-06-1903-2000 Tentang Standard Indonesian Rubber (SIR)

\section{Analisis Finansial}

Dalam studi kelayakan bisnis ada beberapa aspek yang harus di teliti dalam merencanakan, memulai atau menjalankan sebuah proyek, diantaranya adalah aspek hukum, tehnik, ekonomis, pasar, manajemen, sosial dan finansial.

Analisis finansial adalah analisis yang digunakan untuk membandingkan antara biaya dan manfaat untuk menentukan apakah suatu proyek akan menguntungkan selama umur proyek (Husnan dan Suwarsono, 2000)

Menurut Umar (2003:178), tujuan menganalisis aspek finansial dari suatu studi kelayakan proyek bisnis adalah untuk
Standar mutu karet bongkah Indonesia tercantum dalam standar Indonesia Rubber (SIR). SIR adalah karet bongkah (karet remah) yang telah dikering kan dan dikilang menjadi bandela-bandela dengan ukuran yang telah ditentukan. Karet alam SIR-20 berasal dari koagulum (lateks yang sudah digumpalkan) atau hasil olahan seperti lum, sit angin, getah keping sisa, yang diperoleh dari perkebunan karet rakyat dengan asal bahan baku yang sama dengan koagulum. (SNI 06- 2047- 2002 Tentang Standard Bahan Olah Karet). 
Present Value (NPV) atau nilai bersih sekarang yaitu selisih antara Present Value dari investasi dengan nilai sekarang dari penerimaan-penerimaan kas bersih di masa yang akan datang". NPV dapat diartikan sebagai nilai sekarang dari arus kas yang ditimbulkan oleh investasi. Dalam menghitung NPV perlu ditemukan tingkat bunga yang relevan. Metode kedua dari perhitungan investasi adalah $\mathrm{Net} \mathrm{B} / \mathrm{C}$ Ratio yang dilakukan untuk melihat berapa manfaat yang diterima oleh sebuah usaha untuk setiap satu rupiah pengeluaran untuk usaha tersebut. Menurut Ibrahim (2003:151), "Net Benefit Cost Ratio merupakan perbandingan antara net benefit yang telah di discount positif (+) dengan benefit yang telah di discount negative (-). Metode ketiga yang digunakan untuk perhitungan investasi adalah Internal Rate of Return (IRR). Ibrahim (2003:147), "mengemukakan bahwa Internal Rate of Return (IRR) adalah suatu tingkat discount rate yang menghasilkan Net Present Value sama dengan nol (0)". Tujuan dari menghitung IRR adalah untuk mengukur atau membandingkan sejauh mana kemampuan suatu usaha tersebut untuk dapat memberikan keuntungan dibandingkan dengan berinvestasi di Bank. Metode keempat yang digunakan untuk melihat waktu pengembalian investasi dari usaha tersebut di gunakan alat analisis yang bernama PayBack Periods (PBP). Menurut Pasaribu (2012:73), “jangka waktu pengembalian modal investasi yang akan dibayarkan melalui keuntungan yang diperoleh proyek tersebut disebut PayBack Periods".

\section{METODE PENELITIAN}

Penelitian ini menggunakan metode studi kasus. Objek penelitian ini hanya dibatasi pada industri pengolahan karet pada PT Aceh Rubber Industries di wilayah Kabupaten Aceh Tamiang. Ruang Lingkup penelitian ini meliputi kelayakan finansial pada bisnis produk karet remah menjadi karet SIR 20. Pengumpulan data responden diperoleh dari pengusaha pengolahan karet. Data yang digunakan adalah data primer (wawancara, Observasi, Quisioner) dan data sekunder (pustaka). Variabel sebagai berikut : a. Kapasitas Produksi (Ton/Thn), b. Biaya Investasi (Rp/Thn), c. Biaya Tenaga Kerja (Orang/Thn) d.Biaya Produksi dan Pemeliharaan ( $\mathrm{Rp} / \mathrm{Thn}$ ) Produksi (Ton/Thn) f.Pendapatan Kotor ( $\mathrm{Rp} / \mathrm{Thn}$ ) g.Pendapatan Bersih (Rp/Thn). Metode Analisis dan Pengujian Hipotesis Sesuai dengan hipotesis yang telah dirumuskan, maka hipotesis diuji dengan menggunakan analisis kelayakan yaitu : NPV, IRR, Net B/C, dan Pay Back Periods.

\section{Hasil Penelitian \\ Tenaga Kerja}

Pengunaan tenaga kerja merupakan salah satu faktor yang sangat penting dalam kegiatan operasional usaha pengolahan karet SIR 20 di PT.Aceh Rubber Industries. Pengunaan tenaga kerja yang efesien dan efektif dapat mempengaruhi terhadap pengeluaran biaya produksi dalam menjalankan usaha industri karet SIR 20.

Tabel 4.Tenaga kerja yang digunakan pada usaha pengolahan karet SIR 20 meliputi

\begin{tabular}{|c|c|c|c|c|c|c|}
\hline No & Tahun & $\begin{array}{c}\text { Pimpinan/ } \\
\text { (Org) }\end{array}$ & $\begin{array}{c}\text { Tenaga } \\
\text { Adm (Org) }\end{array}$ & $\begin{array}{c}\text { Karyawan } \\
\text { Pelaksana (Org) }\end{array}$ & $\begin{array}{c}\text { Pekerja } \\
\text { Pabrik (Org) }\end{array}$ & Jlh (Org) \\
\hline 1 & 2013 & 7 & 11 & 29 & 44 & 91 \\
2 & 2014 & 7 & 11 & 29 & 44 & 91 \\
3 & 2015 & 7 & 11 & 29 & 44 & 91 \\
4 & 2016 & 7 & 11 & 29 & 44 & 91 \\
5 & 2017 & 7 & 11 & 29 & 44 & \\
\hline
\end{tabular}

Sumber: Data Sekunder, 2018 (diolah) 


\section{Biaya Produksi}

Tabel 5. Rata-Rata Biaya Produksi Selama 5 Tahun Terakhir Pada Industri Pengolahan SIR 20 di PT. Aceh Rubber Industries Kabupaten Aceh Tamiang, 2018

\begin{tabular}{|c|c|}
\hline Tahun & Biaya Produksi \\
\hline 2013 & 9.263 .860 .580 \\
2014 & 10.167 .330 .830 \\
2015 & 10.992 .251 .555 \\
2016 & 12.469 .815 .080 \\
2017 & 14.196 .647 .980 \\
\hline Jumlah & 57.089 .906 .025 \\
\hline Rata-Rata & 11.417 .981 .205 \\
\hline
\end{tabular}

Sumber: Data Sekunder, 2018 (diolah)

\section{Produksi}

Tabel 6 Rata-rata Produksi selama 5 tahun terakhir pada Industri Pengolahan SIR 20 di PT. Aceh Rubber Industries Kabupaten Aceh Tamiang,2018

\begin{tabular}{|l|c|c|}
\hline \multicolumn{1}{|c|}{ No } & Tahun & Produksi (Kg) \\
\hline 1 & 2013 & 698.450 \\
2 & 2014 & 795.550 \\
3 & 2015 & 843.765 \\
4 & 2016 & 951.650 \\
5 & 2017 & 1.075 .620 \\
\hline \multicolumn{2}{|l|}{ Jumlah } & 4.365 .035 \\
\hline \multicolumn{2}{|l|}{ Rata-rata } & 873.007 \\
\hline
\end{tabular}

Sumber: Data Sekunder, 2018 (diolah)

\section{Pendapatan}

Tabel 7. Rata-RataPendapatan Kotor dan Pendapatan Bersih Selama 5 Tahun Terakhir Industri Pengolahan SIR 20 di PT. Aceh Rubber Industries Kabupaten Aceh Tamiang, 2018

\begin{tabular}{|c|l|l|l|l|}
\hline No & Tahun & $\begin{array}{l}\text { Pendapatan } \\
\text { Kotor (Rp) }\end{array}$ & $\begin{array}{l}\text { Total Biaya } \\
\text { Produksi (Rp) }\end{array}$ & $\begin{array}{l}\text { Pendapatan } \\
\text { Bersih (Rp) }\end{array}$ \\
\hline 1 & 2013 & 10.825 .975 .000 & 9.263 .860 .580 & 1.562 .114 .420 \\
2 & 2014 & 13.126 .575 .000 & 10.167 .330 .830 & 2.959 .244 .170 \\
3 & 2015 & 14.344 .005 .000 & 10.992 .251 .555 & 3.351 .753 .445 \\
4 & 2016 & 17.129 .700 .000 & 12.469 .815 .080 & 4.659 .884 .920 \\
5 & 2017 & 20.974 .590 .000 & 14.196 .647 .980 & 6.777 .942 .020 \\
\hline \multicolumn{2}{|c|}{ Jumlah } & 76.400 .845 .000 & 57.089 .906 .025 & 19.310 .938 .975 \\
\hline \multicolumn{2}{|c|}{ Rata-rata } & 15.280 .169 .000 & 11.417 .981 .205 & 3.862 .187 .795 \\
\hline
\end{tabular}

Sumber: Data Sekunder, 2018 (diolah)

\section{Analisis Kelayakan Finansial}

Tabel 8, Indikator Penilaian Kelayakan Usaha Pengolahan SIR 20 di PT.Aceh Rubber

\begin{tabular}{|c|l|c|l|l|}
\hline No & \multicolumn{1}{|c|}{ Indikator Penilaian } & Batas Nilai & Nilai & Kriteria \\
\hline 1 & Net Present Value (NPV) & 0 & 6.871 .582 .204 & Layak \\
2 & Internal Rate of Return (IRR) & $5,25 \%$ & $24,1 \%$ & Layak \\
3 & Net Benefit Cost Ratio (Net B/C) & 1 & 1.75 & Layak \\
4 & Payback Period (PBP) & $5 \mathrm{thn}$ & $3,3 \mathrm{Thn}$ & Layak \\
\hline
\end{tabular}


Catatan : Tingkat suku bunga yang berlaku saat penelitian ini adalah sebesar 5,25\%

(Sumber : BI Rate Juli-Agustus 2018 Bank Indonesia (BI) )

Dari table 8 diatas dapat dilihat bahwa berdasarkan pada hasil perhitungan investasi dimana NPV $=6.871 .582 .204$ (lebih besar dari nol), yang artinya usaha tersebut layak untuk dilanjutkan. Rata-rata IRR $=24,16 \%$ lebih besar dari tingkat bunga yang berlaku 5,25\% sehingga usaha tersebut layak untuk diusahakan dan rata-rata Net $\mathrm{B} / \mathrm{C}$ Ratio $=1,75$ (lebih besar dari 1) maka usaha tersebut layak untuk dikembangkan bila ditinjau dari aspek segi finansial, dilihat dari kemampuan payback period (PBP) usaha ini relatif cepat dapat mengembalikan modal, tepatnya rata-rata 3,3 tahun (lebih kecil dari umur proyek), maka usaha tersebut layak untuk diusahakan dan dikembangkan.

\section{Kesimpulan :}

1. Tenaga Kerja yang digunakan berjumlah 91 orang, 44 orang pekerja pabrik, 29 orang karyawan pelaksana, 11 orang tenaga administrasi, dan pimpinan/kepala 7 orang

2. Total biaya produksi yang dikeluarkan oleh pengusaha dalam usaha industri pengolahan karet SIR 20 didaerah penelitian selama 5 tahun adalah Rp. 57.089.906.025

3. Pendapatan kotor yang diperoleh oleh pengusaha dalam usaha industri pengolahan karet SIR 20 didaerah penelitian selama 5 tahun sebesar Rp.76.400.845.000 dan pendapatan bersih diperoleh sebesar Rp. 19.310.938.975

4. Hasil perhitungan investasi diperoleh $\mathrm{NPV}=6.871 .582 .204$ (lebih besar dari nol), yang artinya usaha tersebut layak untuk dilanjutkan. Rata- rata IRR $=24,16 \%$ lebih besar dari tingkat bunga yang berlaku 5,25\% sehingga usaha tersebut layak untuk diusahakan dan rata-rata Net $\mathrm{B} / \mathrm{C}$ Ratio = 1,75 (lebih besar dari 1) maka usaha tersebut layak untuk dikembangkan payback period (PBP) usaha ini relatif cepat dapat mengembalikan modal tepatnya ratarata 3,3 tahun (lebih kecil dari umur proyek)

\section{Saran}

Memperhatikan pembelian dan pensortiran bahan baku, agar nantinya mutu dari karet SIR 20 tetap terjaga. Dengan menjaga mutu standart Indonesia rubber tersebut terpenuhi

\section{DAFTAR PUSTAKA}

Badan Standardisasi Nasional. 2002. Standard Nasional Indonesia (SNI) 06-20472002 Tentang Bahan Olahan Karet. Badan Standardisasi Nasional Indonesia

Badan Standardisasi Nasional. 1999. Standard Nasional Indonesia (SNI) 06-1903 2000.

Husnan, M \& Suwarsono. 2000. Studi Kelayakan Proyek. UUP. AMP YKPN, Yogyakarta

Ibrahim, M.Y. 2003. Studi KelayakanBisnis. Rineka Cipta, Jakarta.

Mubyarno dan Suratno. 2014. Metodelogi Penelitian Ekonomi, Yayasan Agronomika, Yogyakarta

Nazir, Moh. 2005. Metode Penelitian, Cetakan keenam, Ghalia Indonesia, Jakarta

Pasaribu, A. M. 2012. Perencanaan dan Evaluasi Proyek Agribisnis Konsep dan Aplikasi. Lily Publisher, Yogyakarta

Soekartawi. 2000. Pengantar Agroindustri. Rajagrafindo Persada, Jakarta . 2001. Pengantar Agroindustri. Rajagrafindo Persada, Jakarta 2005. Pengantar Agroindustri. Rajawali Press, Jakarta

Sudarman, Ari. 2004. Teori Ekonomi Mikro. BPFE UGM, Yogyakarta

Sugiyono. 2008. Metode Penelitian Bisnis, Alfabeta, Bandung

Umar, H. 2003. Studi Kelayakan Bisnis, Gramedia Pustaka Utama, Jakarta

Ummaya, F. 2015. Analisis Pay Back Period (Periode Pengembalian Modal) Usahatani Rambutan (Nephelium lappaceum) di Kecamatan Peureulak Kabupaten Aceh Timur. Skripsi Jurusan Agribisnis Fakultas Pertanian Universitas Samudra, Aceh

Wignjosoebroto, Sritomo. 2003, Pengantar Teknik \&Manajemen Industri Edisi 
Pertama, Penerbit Guna widya, Jakarta 